\title{
The Impact Of Social Media On Fraternal Organizations: Ethical Concerns
}

Craig A. Escamilla, Lamar University, USA

Katharine A. Fraccastoro, Lamar University, USA

Emily Blanke, Lamar University, USA

\begin{abstract}
This case study concerns how the personal behavior of students involved in fraternal organizations is depicted in social media, and how that behavior impacts the organization and its image. The legal and ethical implications of individuals' behaviors in social media has become a major issue for many organizations. This case follows an example of a fraternal organization and how the governing body must handle the information members post on social media. The mission of many fraternal organizations is to champion or contribute to specific causes. Members' social media postings may reflect poorly on the organization and may not always align with the principles of the organization. This case examines how those postings impact the organization, and what it can do to mitigate the effects. The ethical issues that can affect the actions of both the governing body and the members are probed throughout the case.
\end{abstract}

Keywords: Ethics; Ethical Issues; Social Media Organizational Image

Suggested Courses: Business Ethics; Marketing Management; Organizational Behavior

arah, the Chapter President of Epsilon Gamma Kappa, opened her email to the following messages
Saturday morning.

The first email was from a member in her chapter about another member, Katie. Katie posted a status on Facebook that said,

"Just had the worst flight of my life!! This kid had turrets or something and wouldn't stop screaming, and his parents didn't do anything! They shouldn't be allowed on a plane again." Ashley, a fellow member, commented "This is uncalled for! I know from experience with my brother that they CANNOT help it! I would be livid if someone ever said this about Caleb!!"

The next email was from Samantha. She sent a picture that Allie, a member of Epsilon Gamma Kappa, posted to her Snapchat Story. The picture was of her little sister in the chapter, Brie, holding a paddle and pretending to hit someone with the caption "Can't wait for new Baby Kappas!"

Haley, a member of Sarah's executive board, asked "Are we worried about this?" in regard to a post made by another member. The picture was at a local bar where you could see the bar full of alcohol behind two members.

The President of a local fraternity sent Sarah an email with a screenshot of a tweet from Brooke Daniels, a chapter member. The tweet read

"*sees black family walk in restaurant*

'Not getting a tip tonight!','

Sarah also had 13 emails from various chapter members and members of other chapters about an email sent from her Vice-President (VP) for Recruitment to the chapter. The email read: 
"Recruitment is this weekend and I wanted to clear some things up. We need to fix our image. We have to recruit girls like us! We only want top recruits! In order to make this happen, I am creating a few new recruitment rules this year.

1. You must get your nails done professionally.

2. Your hair must be dyed blond or so dark it's almost black. I don't want to see your natural hair!! Nights 1, 2, and 3, everyone will wear straight hair, no headbands, and nights 4 and 5, you must curl your hair and pin back one side! If you can't do your own hair, make sure to book an appointment with a professional!

3. I will be inviting someone to give spray tans at the house. You must pay for this yourself, but it is required for every member!

4. You must get all outfits approved by me. (At least 10 of the items you wear this week must be a designer label item! How do you expect to get rich girls if we look like we shop at Target!?)

5. Make-up must be done with the approved color pallet and red lipstick. No exceptions to this!

If you have a problem with any of these things, I will expect your letter of resignation before recruitment week starts!"

Sarah called a meeting with her executive board to decide what actions should be taken to address the situations in her email. Below is the transcript of their meeting.

Sarah: I have printed all the emails of questionable social media posts we need to discuss for each of you. We have some issues we need to get on top of quickly!

Elizabeth (VP Risk Management): I saw the post from Allie on Snapchat last night. I texted her immediately to take it down, but I'm afraid it was already sent along to Dr. Jones since he is over Student Life for the University. I think we need to schedule a meeting with him to be proactive before the university sanctions us.

Andrea (VP Marketing): I agree, but I think we also need to put Allie on probation. She crossed the line and put our chapter in danger of being suspended or worse. Hazing isn't a joke and she knows how much trouble it can get us in if the university even suspects we are promoting hazing new members. I also think we need to jump in on the racist comment Brooke made. That is equally as bad and could get us in trouble!

Elizabeth: I think we need to ask Brooke to resign. That was totally unacceptable. I have been getting texts all day from sisters who want to quit because of her tweet. We promote our organization as being diverse, so it goes against that for us to let this slide.

Sarah: I just want to remind both of you that we aim to help women improve themselves. I think we need to think through all the options before we make any decisions.

Andrea: Should we talk about Katie's post? I know Ashley got pretty upset about it.

Elizabeth: She shouldn't have said that, but I'm not sure it warrants action on our part, other than to ask her to delete the post.

Andrea: I disagree. I think we need to step in anytime a member of our organization offends another member. It could grow into something bigger than just the two of them if we aren't careful.

Sarah: Considering how many issues we had this weekend alone, I am going to suggest we do something proactive with the whole chapter. It's like the whole chapter lost its mind about what is appropriate over night!

Kim (VP Standards): I agree about talking to the whole chapter, but I think it's more important for us to jump on top of Lani's email. As our VP Recruitment and a member of our executive board, she definitely should have known better. I have already received an email from Headquarters and this has the potential to go viral if someone posts it 
on the internet. Headquarters will step in soon, but we need to show that we know it's a problem and we are on top of it before they do.

Sarah: Oh gosh. They emailed me too, but I was hoping to ignore it for a few more hours while we figure out what to do. I didn't bring this up yet, but Haley also sent me a picture of Jessica, Emma, and Isabella at Tony's last night in front of the bar. Emma was holding a beer and you can see the whole bar behind them. I'm not sure it's worth pursuing, but I'll leave that up to the board to decide. Why don't we take a break for lunch and think about our options? We can come back together in a few hours and decide what to do about each issue.

\section{History of the Organization}

Epsilon Gamma Kappa (EGK) is a social sorority that is nationally based and made up of almost 150 individual chapters. Women ages 18-25 who are enrolled as full time students at a university are the target market for EGK. EKG is over 130 years old. This longevity is part of what makes the organization successful.

The Organization falls under the National Panhellenic Conference and is governed by the Constitution of the Panhellenic Conference as well as its own National Policies and Procedures. Each chapter must follow these documents, but has the autonomy to create their own bylaws to further govern their chapter. The organizations must also follow all university policies and Federal and State Laws. The executive board, comprised of 10 officers and 1 advisor, create this set of bylaws with input from them once each year. Some of the officers include a Chapter President, VP of Standards, VP of Public Relations and Marketing, and VP of Risk Management. The executive board leads the chapter with some input from the advisor, when necessary. The organizations aim to be selfsufficient and run without much oversight from the National Headquarters.

The Vice President of Standards leads a board, the Standards Board, whose job it is to meet with members who violate the organization's standards. These meetings are held to discuss the violation, hear the member's side of the story, and potentially identify disciplinary action to remedy the situation. Such actions can include anything from an apology to a member, to a written assignment, to extra community service, to placing a member on suspension or asking her to resign.

One of the main purposes of EGK is to provide women with the resources to develop leadership skills, networking skills, and personal and professional growth opportunities. The National Headquarters develop many resources for the chapters to use to lead women toward these goals. Chapters can plan events and workshops that aim toward harnessing skills such as time management, conflict resolution, and communication.

\section{History of the Industry}

Greek Organizations have deep roots in American Society. They began as groups to debate and discuss current events and literature. The first recorded Greek Letter Organization was Phi Beta Kappa, founded at the College of William and Mary in 1775. This was later transitioned into an Honor Society.

Epsilon Gamma Kappa is part of the College Panhellenic Conference (CPC), a university sector of the National Panhellenic Conference (NPC) and made up of 26 nationally-based Sororities. As mentioned, while EGK can create their own bylaws and guidelines, they must fall within the parameters set by the National Panhellenic Conference.

Chapter Houses did not become common until the 1890s. There was no need before this time, but as organizations grew in numbers, it became more difficult to find meeting places. This led the way to building houses in which members could meet and live. This also led to a change in the makeup of Greek Letter Organizations and their priorities. Since members were spending all day every day together in the same house, they began to integrate more social activities into the organizations' daily operations. Due to the increase in time spent together, recreational activities came to the forefront.

Greek Letter Organizations recruit members through a process called "Rush" or "Recruitment." The term "Rush" came about because originally fraternities and sororities "rushed" to get to the new freshman on campus before 
another organization got to them first. In modern times, this process has been coined "recruitment" to show the active role chapters and their members take in finding and recruiting the best members for their organizations.

Traditionally, Greek Letter Organizations were kept a secret, but now, the organizations are very public about their existence and even most of their operations. Each organization still has their ritual and initiation rites that are kept secret from the outside world, however. Although the organizations are open about operations and encourage spreading the word about their existence, they are still exclusive in many ways. Non-members are asked not to wear the organization's letters or badge/crest, and there are many events deemed "for members only." This exclusivity can lead to misunderstandings and misperceptions about Greek Letter Organizations and their activities.

Greek organizations have been around since the beginning of America as a country, and have experienced and survived many of the issues America and its citizens have faced, including: The Revolutionary War, The Civil War, World Wars I and II, the Great Depression, The Vietnam War, and the Civil Rights Movement in the 1960s. These events definitely had an impact on the organizations, their members, and how they operate.

Greek Letter Organizations charge members dues, which depend on the dues of national organizations, fees the chapters pay to universities, umbrella organization dues, whether an organization has a house and if a member lives in the house, and other expenses or activities of individual chapters.

Greek Letter Organizations have always had to make branding decisions to market themselves to Potential New Members, Parents, University Officials, and the general public. It is only with the recent popularity of social media that Greek Letter Organizations have begun integrating these platforms into their daily operations to mold their image for the public.

There are some general perceptions about Greek Life that society has. Greeks are seen as alcoholic, sometimes dumb, irresponsible, rich kids. Canden Schwantes, $(2004$, p. 1) says, "When Greek life was portrayed, its members came off as ditzy, rich, preppy, party animals" and Courtney Hayes $(2015$, p. 4) points out that movies like "Neighbors" give the idea that fraternities spend every night partying and hazing, that fraternities only fundraise for personal gain to fund their next party, and that meetings are only to discuss party plans for the next event. Movies, TV shows, books, and other media tend to portray Greek Life in this way for the entertainment value it brings. This leads to misunderstandings about the purpose, goals, and mission of Greek Organizations.

News Sites also feed this image, choosing to feature the negative stories surrounding Greek Life more often than the positive things organizations do. This increases viewership, and is often more interesting than the positive aspects of Greek Life. It is something that Greek Organizations must be aware of, however.

Greek Letter Organizations can use social media to combat some of these perceptions about Greek Life. While organizations can control their image to some degree by the posts on their public social media pages, organizations have a more difficult time controlling what information is spread by individual members. This is a common problem for any organization comprised of young adults who may not always see the bigger picture, but it is magnified for organizations that already have negative perceptions surrounding them.

Greek Letter Organizations have typically been single sex organizations. Due to the further push for equality that America is facing now, some people are claiming that it is unconstitutional to maintain single sex organizations at any level. These groups believe that such clubs should be banned from college campuses. This has led to some universities removing support for Greek Life on their campus. Some campuses have gone as far as to say that any member of a Greek Organization is not eligible for Scholarships or leadership positions within that University.

\section{TEACHING NOTE}

\section{Synopsis}

Sarah, Chapter President of Epsilon Gamma Kappa (EGK), and her executive board must deal with the fallout from a number of members' social media posts. The issues include: a negative Facebook post about a child on a flight 
with Turrets' Syndrome, a Snapchat photo implying hazing during the upcoming recruitment and initiation process for new members, a photo of current members possibly consuming alcohol, a Tweet featuring negative racial stereotypes, and an email from the chapter's VP Recruitment outlining discriminatory expectations of members' appearance for recruitment activities. The case provides an overview of EGK, as well as industry and historical information about student fraternal organizations.

\section{Teaching Objectives}

This case has 4 general teaching objectives:

1. To encourage student reflection on the legal and ethical implications of their social media behavior and how it affects others including social organizations, employers, etc.

2. To examine the issues businesses/organizations face in maintaining an image and how negative information can impact the business/organizational image.

3. To assess an organization in terms of its strengths, weaknesses, opportunities and threats to gain a broader perspective that can help students recognize inappropriate social media behaviors that could impact the individual and the business/organization in negative ways.

4. To develop solutions to address the increasing legal and ethical implications of social media on businesses/organizations.

\section{Teaching Suggestions}

This is a case study concerning how the personal behavior of students involved in fraternal organizations is depicted in social media and how that behavior impacts the organization and its image. The legal and ethical implications of individuals' behaviors in social media is becoming a major issue for many organizations. This case follows an example of a fraternal organization and how the governing body must handle the information their members post on social media. Most fraternal organizations have philanthropic ideals as the foundation of their creation. They constantly have to work to maintain their image in light of the common stereotype of a fraternity/sorority as a party organization as depicted in "Animal House." The mission of many of these organizations is to champion or contribute to specific causes. Members' social media postings may reflect poorly on the organization and may not always align with the principles of the organization. When members' post inappropriate messages/images it reflects on the organization. This case examines how those postings impact the image and mission of the organization and what the organization can do to mitigate or eliminate those postings and their effects. The ethical issues that can affect the actions of both the governing body and the members are probed throughout the case. Specific questions that could be used to guide the discussion and analysis of this case include the following:

1. What are your thoughts about posting on social media? How does it reflect on you? Others? Are there any ethical or legal considerations you personally have to consider when posting on social media? Are there any ethical or legal considerations businesses/organizations have to consider when employees/members post on social media?

2. What does "image" mean to you? To a business or organization?

3. What is the image for a Greek organization? How do you think the Greek organization wants you to think of them?

4. How would you characterize the EGK organization? What are its strengths and weaknesses? What opportunities and threats do they face? (Conduct a SWOT analysis for this Greek organization)

5. What member actions are most problematic for the organization? What possible actions could the organization take to resolve the issues?

\section{Areas for Discussion/Analysis}

What are your thoughts about posting on social media? How does it reflect on you? Others? Are there any ethical or legal considerations you personally have to consider when posting on social media? Are there any ethical or legal considerations businesses/organizations have to consider when employees/members post on social media? 
Student answers may vary. Some may feel they have the right to post whatever they want on social media. Other students may be more conservative about what they post. Some may feel that when using platforms like "Snapchat" since it is a temporary, short duration, post it is not as harmful as posts to other platforms that are longer in duration like "Facebook." This is not true. Once information is put in a public platform, many people can see it regardless of the length of time it is posted. Try to steer the conversation toward what posts tell others about the individual as well as how posts reflect on people/businesses/organizations that interact with that individual.

Ethical and legal considerations for the individual can be a very broad topic area. Students could discuss posts that show people breaking various laws that they have seen. Numerous reports abound of law enforcement using people's posts to arrest and prosecute them. However, there are many posts in different platforms that may not be illegal, but are questionable as to whether or not they would be considered appropriate behavior. The legal aspects are easier to discuss than the ethical issues. Ethics are moral principles or values that govern behavior. Ethics are based on the moral values of society. Our most basic ethical and moral values have been codified into laws. Laws are the minimum level of acceptable behavior. Ethics are considering behaviors above the minimum that should be acceptable. Discussion on the ethical issues could be prompted by asking students if they have seen any posts that contained offensive or inappropriate legal behaviors and, then, asking why they believe that is unethical or unacceptable.

As for businesses/organizations, they have carefully built reputations that must be maintained, so they would obviously prefer to avoid any inappropriate or questionable posts on their own social media sites. The bigger question is does the business/organization have any responsibility when employees/members make posts that include and/or reference the company? The answer is yes. Business and organizations have a social contract with their consumers and they do not want to violate that contract or trust. Every employee/member is a representation of the company to the consumer, therefore, their social media posts are of concern to employers/organizations. Not every post would be considered unethical, but the discussion should be guided toward what type of posts could potentially harm the business/organization.

Businesses/organizations also have legal responsibilities to provide a workplace that is free of physical and psychological threats for all employees/members. According to the Occupational Safety and Health Act's general duties clause (Lussier \& Hendon, 2016), each employer

1. Shall furnish a place of employment that is free from recognized hazards that are likely to cause death or serious physical harm to employees;

2. Shall comply with occupational safety and health standards and all rules, regulations, and orders issued pursuant to this Act which are applicable to his own actions and conduct.

The general duties clause also states that each employee has a duty to comply with occupational safety standards, rules, and regulations.

According to Title IX of the United States Education Amendments of 1972 (U.S. Department of Education, 2015), no person in the United States shall, on the basis of sex, be excluded from participation in, be denied the benefits of, or be subjected to discrimination under any education program or activity receiving Federal financial assistance. Since Title IX applies to all education institutions receiving federal assistance, the class discussion may include mention of the law, its requirements, its place at the students' institution, and its impact on the dilemmas discussed in this case.

Thus, employee/member posts can have legal implications for the employer/organization. Employers do have the right to fire employees and organizations can also revoke memberships due to social media posts.

What does "image" mean to you? To a business or organization?

Students usually understand what image is, but may have a hard time putting the concept into words. According to the Merriam-Webster dictionary, image can be defined as "(1) a mental picture or impression of something; (2) a mental conception held in common by members of a group and symbolic of a basic attitude and orientation, or (3) a 
popular conception (as of a person, institution, or nation) projected especially through the mass media." The conversation of image for the student should gravitate toward the impression they project to others about who they are or what they believe (what are their values).

To a business or organization, the image is a vital part of its existence. The image of businesses or organizations is partially based on the functional qualities it has (business - products it carries, location, pricing, store personnel, etc.; organization - ideology it represents, pricing, functions it carries out, etc.) and partially based on the ambiance of psychological attributes (how the business/organization makes the person feel, the mood or tone it sets). One could think of image as the personality a person perceives the business/organization to have. The image created will help determine who interacts with the business/organization.

To have employees or members make posts that are counter to the image of the business/organization would be extremely harmful to the representation the business/organization is trying to provide to the public. When people see information counter to their own beliefs such as negative, unethical, or illegal activities in posts on social media, they will at a minimum distance themselves from those businesses/organizations. They may also boycott those entities and will, most likely, stop purchasing from or participating with those businesses or organizations, thus damaging the economic viability of the business/organization.

What is the image for a Greek organization? How do you think the Greek organization wants you to think of them?

When discussing Greek organizations, the first thought for most students is party. Movies like "Animal House," "Neighbors," and "Neighbors 2" come to mind. While Greek organizations do want members and potential members to have fun and socialize, they do not want the image that most students tend to attribute to them. Greek organizations were established originally as groups to debate and discuss events and literature and have evolved into organizations designed to provide resources to members to develop leadership skills, networking skills, and personal and professional growth opportunities. Most Greek organizations try to dispel the "party" image in favor of a "lifelong community" image in which members support each other in all aspects for their lives, both now and in the future. They have to work to maintain this positive image and market it to potential members, parents, university officials and the general public. Organizations have their own social media platforms to utilize to this effect, but they also have members that post to their own social media as well. They posts by the members can and will effect the organization.

How would you characterize the EGK organization? What are its strengths and weaknesses? What opportunities and threats do they face? (Conduct a SWOT analysis for this Greek organization)

At this point, the instruction may wish to lead students through a company and industry analysis, focusing on the strengths, weaknesses, opportunities, and threats facing EGK based on the fictional data within the case (See Figure 1). This exercise helps students better understand many of the structural, organizational, and brand image challenges facing fraternal organizations. Although students are likely to be familiar with the scenarios presented in the case, leading them through the process of considering the broader issues that allow such scenarios to happen is not only essential for finding appropriate solutions to the case's problems, but also to learning how to address these types of issues within their own fraternal organizations, and in their professional organizations in the future.

EGK is over 130 years old. This longevity is a strength for the organization. EGK also provides many opportunities for its members to develop professional skills. For example, the national organization creates resources that chapters can use to help their members develop these skills. Chapters also plan events such as Chapter Retreats or Academic Workshops where members learn about and work together to improve professional and teamwork skills. There are also a multitude of opportunities for members to be in leadership positions, whether in an executive position or as a committee chair. 
Figure 1 SWOT Analysis

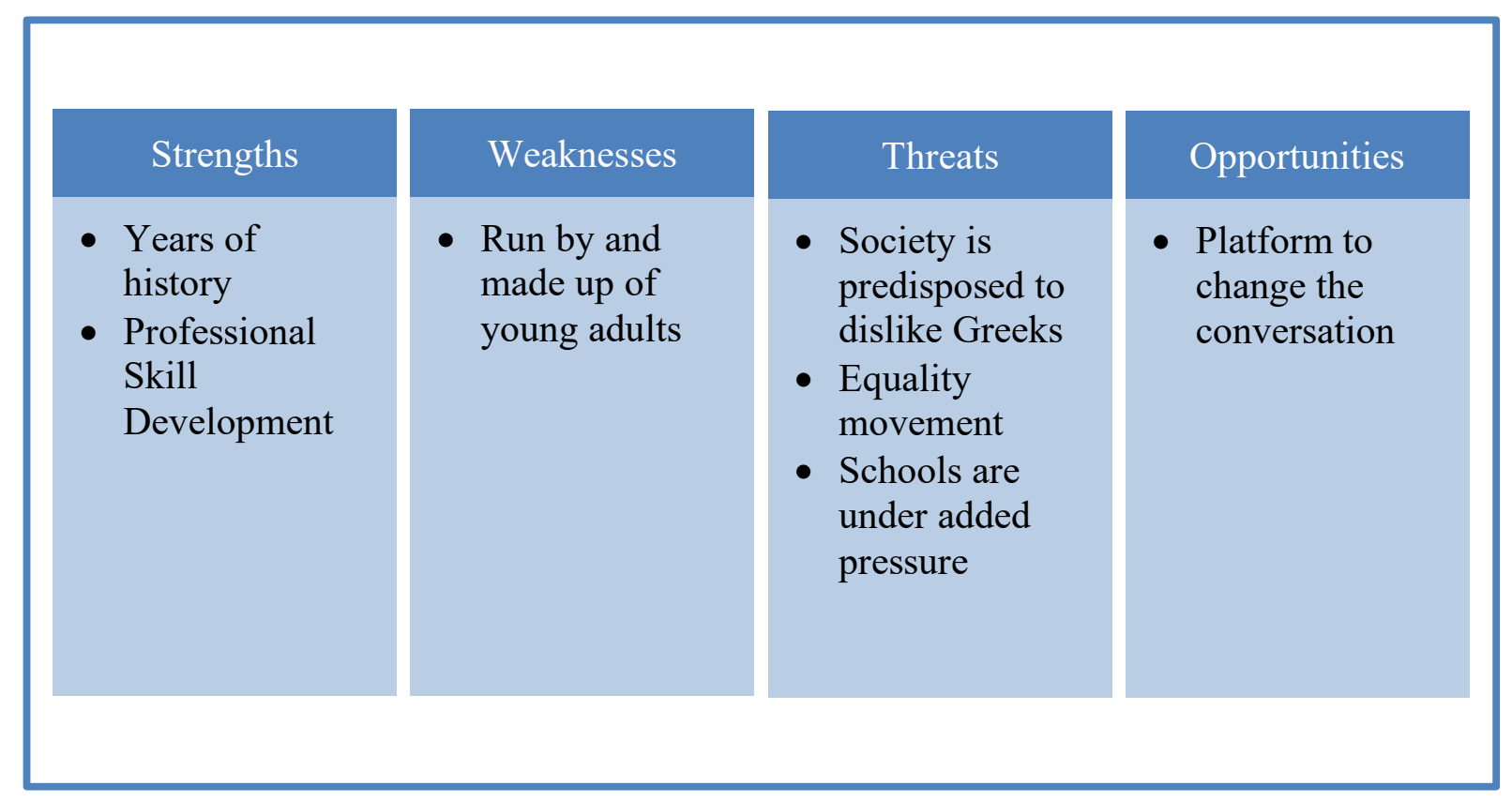

EGK's main weakness is that chapters consist of young adults who don't always see the far reaching implications of their choices. Chapters are encouraged to govern themselves rather than rely on advisors to double check every decision. Advisors are there for guidance, but the organizations run themselves. This can lead to poor decision making and inadequate planning.

EGK has many opportunities, including the ability to change the conversation about Greek Life. Because the organization is made up of thousands of members across the nation, they are in the position to make an impact on the perceptions of Greek Life if they work together.

Many members of society are predisposed to dislike Greek Organizations based on the perceptions portrayed by movies and TV Shows. Also, universities are under increasing pressure to crack down on alcohol and drug abuse, sexual assault, and hazing, all of which are often associated with Greek Organizations and the culture that Greek Life promotes. These challenges pose a threat to EGK's survival and growth potential. Another major threat is the current American equality movement. Some people are claiming that single sex organizations like EGK are unconstitutional and should be banned or forced to accept members of all genders. This would radically change EGK's makeup and priorities, and would likely lead to many other Greek Organizations ceasing to exist.

What member actions are most problematic for the organization? What possible actions could the president take to resolve the issues?

There are many possible solutions for the issues in the case.

One option is to do nothing. While this is clearly not a viable option in this scenario because young adults often need some guidelines and resources for behavior, some students may not see the issues as problematic. If this is the case, the instructor has an opportunity to help students better understand why these issues have far reaching implications for the individuals and organization beyond the present situation.

Another option is to create a social media policy, in conjunction with chapter members, to guide appropriate behavior through social networking. This solution could create a chapter-specific set of guidelines, inviting input from chapter members. Discussion of this solution could center on the importance for subsequent "buy in" of 
involving organization members in organizational change processes, and in the design of codes of ethics and other policies with which members have to live. This solution also allows EGK to include standards that are unique to this chapter and outline the consequences of violating the contract that best represent this chapter. A con of creating a social media contract with members' input is that, depending on the leadership of the chapter, chapters may not take the task seriously. Also, a social contract can still be time consuming to enforce and the chapter must have a group dedicated to following and enforcing the contract.

EGK could also provide further education and training for the Vice President of Marketing and her committee. This could take the form of attending a national training seminar. This solution increases expenses, possibly significantly, but may provide a broader, outside perspective on how other chapters and student organizations are addressing the challenges of social media. Also, this solution presents the possibility of an officer not retaining the information shared at the training and wasting the time, energy, and money associated with the event.

Another option is for the Executive Board to monitor members' social media activities. An advantage to this is that EGK can heavily train the executive members on what is appropriate and what is not and empower them to help teach the rest of the chapter. The challenges are that this requires executive members to constantly monitor social media, which can be a full time job, and that executive members are spot lit more than before and must be extra careful to follow all parts of the social media guidelines themselves. Also, this may alienate executive board members from the rest of the chapter because members fear being caught doing something they aren't supposed to.

One final option is to create a generic named social media account. Some chapters create a Facebook account under a generic name and require members to follow the account so the chapter has a way to discreetly ask members to take down posts. The idea is that if the generic name account, run by an appointee of the chapter, "likes" a member's post, the member has 24 hours to remove it or face disciplinary action. This solution is somewhat hidden from outsiders, which prevents the chapter from "airing its dirty laundry" in public. This solution is also nonconfrontational. A simple "like" on Facebook comes across better than a call from an executive board member. A challenge is that someone still has to monitor this account every day. Also, forcing members to follow a specific account like this once again makes many members feel targeted or like they are being monitored. It is not conducive to the fraternal bond many chapters hope to create.

Students may present other solution ideas from their own experience with fraternal organizations facing similar situations. This kind of discussion should be encouraged. Students may also present suggestions for addressing the specific concerns in the scenarios. While this is perfectly acceptable, the instructor should encourage a broader discussion that looks beyond the urgent issues at hand, and trains students to think, instead, about future implications and long-term solutions to the underlying cultural problems that allow or promote inappropriate social media use/behavior.

\section{AUTHOR BIOGRAPHIES}

Craig A. Escamilla (contact author), MBA, a serves as the Executive Director of Retention and Student Success at Lamar University (Beaumont, TX). He also teaches management and organizational behavior courses in Lamar University's College of Business, where he previously served as Director of Accreditation and Assessment. Prior to joining Lamar's faculty, Craig served as Executive Director of the Symphony of Southeast Texas in Beaumont for seven years. E-mail: caescamilla@lamar.edu

Dr. Katherine A. Fraccastoro, Ph.D, Professor of Marketing, The William E. and Katherine F. Fouts Faculty Scholar in Business, Lamar University. She received her Ph.D. from Louisiana State University. Her research interests include consumer behavior issues related to product pricing, cultural acceptance issues, entrepreneurship, and marketing education. She has published several referred papers on these and related issues in conference proceedings and journals such as the Journal of Consumer Behavior, Marketing Letters, Journal of Higher Education Policy and Management, and Communications of the Association for Information Systems. E-mail: fraccastka@lamar.edu 
Emily Ehrlich graduated from Lamar University with a Bachelors of Business Administration in Marketing in 2016. While at Lamar, she held positions as VP Intellectual Development, VP Chapter Relations and Standards, and Chapter President of Alpha Chi Omega. Emily currently serves as eCommerce Operations Coordinator for United Supermarkets, LLC in Lubbock, Texas. E-mail: emilyblanke3204@gmail.com

\section{REFERENCES}

Hayes, C. (2015). Greek Life in the Media Vs. Reality. The Odyssey (August 31, 2015). Retrieved from https://beta.theodysseyonline.com/greek-life-media-reality

Lussier, R. N. \& Hendon, J. R. (2016). Human Resources Management, 2nd Edition. Sage.

Schwantes, C. (2004). Media and Hollywood inaccurately represents college Greek Life. The Pendulum (October 7). Retrieved from http://www.elon.edu/e-web/[endulum/Issues/2004/10_7/opinions/greek.xhtml

U.S. Department of Education. (2015). Title IX and Sex Discrimination. April. Accessed June 27, 2017.

https://www2.ed.gov/about/offices/list/ocr/docs/tix_dis.html 